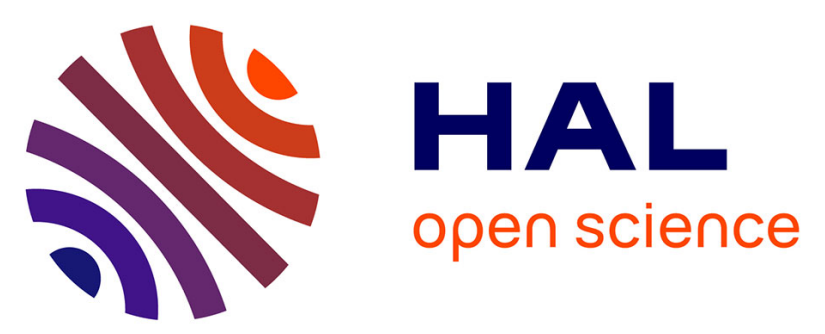

\title{
Scale inhibition effect of Hylocereus undatus solution on calcium carbonate formation
}

\author{
Tony Lourteau, Hana Berriche, Karima Kécili, Véronique Heim, Damien \\ Bricault, Marc Litaudon, Xavier Cachet, Fanny Roussi, Hubert Perrot, Olivier \\ Horner, et al.
}

\section{To cite this version:}

Tony Lourteau, Hana Berriche, Karima Kécili, Véronique Heim, Damien Bricault, et al.. Scale inhibition effect of Hylocereus undatus solution on calcium carbonate formation. Journal of Crystal Growth, 2019, 524, pp.125161. 10.1016/j.jcrysgro.2019.125161 . hal-02910987

\section{HAL Id: hal-02910987 https://hal.sorbonne-universite.fr/hal-02910987}

Submitted on 6 Jan 2021

HAL is a multi-disciplinary open access archive for the deposit and dissemination of scientific research documents, whether they are published or not. The documents may come from teaching and research institutions in France or abroad, or from public or private research centers.
L'archive ouverte pluridisciplinaire HAL, est destinée au dépôt et à la diffusion de documents scientifiques de niveau recherche, publiés ou non, émanant des établissements d'enseignement et de recherche français ou étrangers, des laboratoires publics ou privés. 


\title{
Scale inhibition effect of Hylocereus undatus solution
}

\section{on calcium carbonate formation}

Tony Lourteau ${ }^{\mathrm{a}}$, Hana Berriche ${ }^{\mathrm{a}, \mathrm{b}, \mathrm{c}}$, Karima Kécili $^{\mathrm{c}}$, Véronique Heim ${ }^{\mathrm{d}}$, Damien Bricault ${ }^{\mathrm{b}}$, Marc Litaudon $^{\mathrm{d}}$, Xavier Cachet ${ }^{\mathrm{d}}$, Fanny Roussi ${ }^{\mathrm{d}}$, Hubert Perrot ${ }^{\mathrm{b}}$, Olivier Horner ${ }^{\mathrm{a}, \mathrm{b}}$, Hélène CheapCharpentier ${ }^{\mathrm{a}, \mathrm{b}^{*}}$

${ }^{\text {a }}$ EPF - Graduate School of Engineering, 3 bis, rue Lakanal, 92330 Sceaux, France.

${ }^{\mathrm{b}}$ Sorbonne Université, CNRS, Laboratoire Interfaces et Systèmes Électrochimiques, 4, place Jussieu, F-75005, Paris, France.

c Veolia Eau d'Ile de France, 28, avenue Pesaro, 92739 Nanterre Cedex, France.

d Syndicat des Eaux d'Ile de France, 14, rue Saint Benoît, 75006 Paris, France.

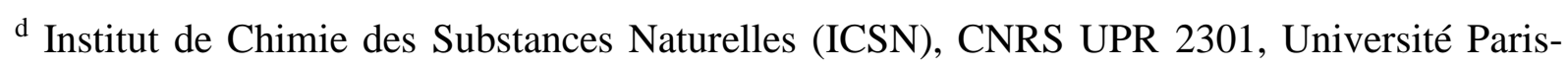
Saclay, 1, Avenue de la Terrasse, F- 91198 Gif-sur-Yvette Cedex, France.

* Corresponding author: Tel.: +33141134285

E-mail address: helene.cheap-charpentier@epf.fr (H. Cheap-Charpentier)

\begin{abstract}
In this paper, the inhibiting properties of an aqueous solution containing Hylocereus undatus towards $\mathrm{CaCO}_{3}$ formation were studied by using fast controlled precipitation and chronoamperometric methods, in order to study the calcium carbonate formation in solution and on a metallic surface, respectively. As a purpose of comparison, the antiscaling properties of citric acid were studied in the same experimental conditions. The results obtained by fast controlled precipitation method showed that Hylocereus undatus solution was more efficient
\end{abstract}


than citric acid to inhibit $\mathrm{CaCO}_{3}$ formation in solution (optimal concentrations of 20 and 24 mg. $\mathrm{L}^{-1}$, respectively). By using the chronoamperometric method, a concentration of citric acid at $160 \mathrm{mg} . \mathrm{L}^{-1}$ was required to totally prevent the precipitation of $\mathrm{CaCO}_{3}$ whereas it was 180 mg. $\mathrm{L}^{-1}$ for Hylocereus undatus solution. The morphology analysis by scanning electronic microscopy and X-ray diffraction revealed that vaterite was favored in the presence of Hylocereus undatus solution, whereas a mixture of calcite and vaterite was obtained with citric acid.

Keywords: A1. Crystal structure; A1. Surfaces processes; A2. Growth from solutions; B1. Calcium compounds

Abbreviations: CA: chronoamperometry; FCP: fast controlled precipitation; H. undatus: Hylocereus undatus; rpm: rotation per minute; SCE: saturated calomel electrode; SEM: scanning electronic microscopy; $t_{p}$ : precipitation time; $v_{p}$ : precipitation rate; XRD: X-ray diffraction.

\section{Introduction}

Scale deposits are widely encountered in many industrial processes $[1,2]$. They may cause some technical problems, such as a decrease in flow rate, a reduced heat transfer and a clogging of membrane filters $[3,4]$. Setting up strategies to prevent or reduce scale formation is an important issue in industry. Currently, the use of chemical inhibitors is a common method to prevent or limit scale formation. Many additives commonly used for scale inhibition contain carboxylic groups in their structure $[5,6]$, which could react with $\mathrm{Ca}^{2+}$ ions. Indeed, organic macromolecules such as polyaspartic acid or polyacrylic acid [7, 8], which could be adsorbed on the active sites of $\mathrm{CaCO}_{3}$ crystals, are usually used as antiscalants. Phosphorus or nitrogen- 
based molecules have proven to be very efficient scale inhibitors [9]. However, the use of such organic compounds could have toxic effects towards environment, e.g. as involvement in eutrophication process [10]. Therefore environmental friendly antiscalants are needed. In the past few years, green inhibitors $[11,12,13]$ have raised great interest because they are biodegradable, non-toxic and do not affect environment [14]. In this respect, some plant extracts, namely Herniaria glabra [15], Spergularia rubra, Parietaria officinalis [16], Bistorta officinalis [2] or Gambier extracts [17], were recently studied for their antiscaling properties and used as green inhibitors. They contain chemical compounds, such as flavonoids, that can react with $\mathrm{Ca}^{2+}$ ions via some specific groups in their structure.

In this work, the antiscaling properties of an aqueous solution containing Hylocereus undatus (H. undatus), towards calcium carbonate formation, were studied by using fast controlled precipitation $[18,19]$ and chronoamperometric [20] methods. The calcium carbonate formation in solution was studied by the Fast Controlled Precipitation (FCP) method, whereas the $\mathrm{CaCO}_{3}$ formation on a metallic surface was investigated by chronoamperometry (CA). H. undatus, whose official name is Hylocereus undatus (Haw.) Britton \& Rose, is from the fruit crop of the dragon fruit. Haworth was the first botanist who described this plant under the name "Cerus undatus Haw." Then few years later, two others botanists, Britton and Rose, classified this plant in Hylocereus undatus. This plant contains some amino acids, sugars, polysaccharides [21], organic acids, fatty acids, and flavonoids [22, 23], which may have an inhibiting effect towards calcium carbonate formation. As a purpose of comparison, the classical antiscaling properties of citric acid solution were studied in the same experimental conditions. Citric acid is also an environment-friendly molecule which can act as scale inhibitor [24, 25] due to the presence of carboxylic groups in its structure that bind with $\mathrm{Ca}^{2+}$ ions [26]. In order to get some insight into the inhibition mechanism, the morphology of scale deposits formed in solution in 
the absence or presence of inhibitors was characterized by scanning electronic microscopy (SEM) and X-ray diffraction (XRD).

\section{Material and methods}

\subsection{Reactants}

Synthetic water used in this work was a pure solution, containing only $\mathrm{Ca}^{2+}$ and $\mathrm{HCO}_{3}{ }^{-}$ions, with an initial $\mathrm{Ca}^{2+}$ concentration of $100 \mathrm{mg} . \mathrm{L}^{-1}$. The tested solution was prepared by dissolving solid calcium carbonate (AnalaR NORMAPUR VWR, 99.7\% purity) in pure water (Milli.Q water, $18.2 \mathrm{M} \Omega \mathrm{cm}$ resistivity and TOC $<5 \mathrm{mg} . \mathrm{L}^{-1}$ ) at the concentration of $500 \mathrm{mg} . \mathrm{L}^{-1}$. The complete dissolution was performed by adding $\mathrm{CO}_{2}$ gas in the solution during $24 \mathrm{~h}$. After the solid dissolution, the $\mathrm{pH}$ of the solution was 5.6. The solution was then filtered with a Millipore filter (514-8073 Whatman, $0.45 \mu \mathrm{m}$ porosity) to remove any impurities. Stock solution of citric acid monohydrate (Sigma-Aldrich, 99\% purity) was prepared in pure water at the concentration of 4 g.L $\mathrm{L}^{-1}$. Dried powdered aerial parts of H. undatus ((Haw.) Britton \& Rose), a Cactaceae of the Magnoliopsida class and the Caryophillidae subclass, were purchased from AuZoma $\odot$ (Madagascar plants, http://www.auzoma.com). An aqueous solution of $H$. undatus was obtained by infusing $2 \mathrm{~g}$ of plant material for $15 \mathrm{~min}$, in $100 \mathrm{~mL}$ of boiling distilled water. The infusion at $2 \%(\mathrm{w} / \mathrm{vol})$ was then strained through a polypropylene microfilter with a pore size of $0.45 \mu \mathrm{m}$. Suitable amounts of this infusion were taken off and diluted in solution for FCP and CA tests.

\subsection{Fast controlled precipitation (FCP) method}

The FCP method has been previously detailed elsewhere [27, 28]. Basically, this method is based on the moderate degassing of the dissolved $\mathrm{CO}_{2}$ by stirring the water sample. It allows characterizing the nucleation step and the homogeneous precipitation of $\mathrm{CaCO}_{3}$ in the absence 
or presence of scale inhibitor. It must be noticed that factors which determine the degassing process in the experimental set-up were strictly controlled: the temperature $\left(30^{\circ} \mathrm{C}\right)$, the stirring rate $(850 \mathrm{rpm})$, the stirrer position and the positions of the measuring electrodes. In these conditions, a nice reproducibility of the FCP method is achieved [29]. All experiments were carried out at $30{ }^{\circ} \mathrm{C}$ in synthetic water containing initially $\left[\mathrm{Ca}^{2+}\right]=100 \mathrm{mg} . \mathrm{L}^{-1}$. During an FCP experiment, the $\mathrm{pH}$ and the resistivity were recorded simultaneously as a function of time, using a pH-meter (Radiometer pHM220) and a conductivity-meter (Radiometer CDM230). The pH and conductivity electrodes were purchased from Radiometer Analytical. Saturated calomel electrode (SCE, Radiometer Analytical) was used as reference electrode. For a given concentration of inhibitor, the scale inhibition efficiency was calculated from the relation:

$\mathrm{E}_{\mathrm{FCP}}=\frac{\int \rho_{0} \cdot d t-\int \rho_{i} \cdot d t}{\int \rho_{0} \cdot d t} \times 100$

where $\rho_{0}$ and $\rho_{i}$ are the resistivities of the synthetic water in the absence and presence of inhibitor, respectively.

\subsection{Chronoamperometry measurements}

CA measurements were carried out as previously described [16]. The initial $\mathrm{pH}$ value in all test solutions was adjusted at 5.6 by bubbling $\mathrm{CO}_{2}$ gas in solution. The working electrode was a rotating copper electrode, and the counter-electrode was a platinum grid. Saturated calomel electrode (SCE) was used as a reference electrode. The potential applied to the working electrode was set at $-1 \mathrm{~V} / \mathrm{SCE}$, which corresponds to the reduction potential of dissolved dioxygen. The hydroxyl ions formed in the vicinity of the electrode increased the local $\mathrm{pH}$, which induced the precipitation of $\mathrm{CaCO}_{3}$ on the metallic substrate $[30,31]$. 
The scaling time was the time necessary to cover the electrode by a layer of $\mathrm{CaCO}_{3}$. It was calculated from the difference between the time at the maximum of the curve and the time when the current reached a constant residual value $(\sim 15 \mu \mathrm{A})$. The precipitation rate was determined by calculating the slope of the curve current versus time.

In order to calculate the scaling inhibition efficiency, $\mathrm{E}_{\mathrm{CA}}$, of the inhibitor, the precipitation rate on a metallic surface was obtained from the chronoamperometric curve by calculating the slope of the curve current versus time. Then, $\mathrm{E}_{\mathrm{CA}}$ was calculated from the relation:

$\mathrm{E}_{\mathrm{CA}}=\frac{v_{p 0}-v_{p i}}{v_{p 0}} \times 100$

where $v_{p 0}$ and $v_{p i}$ were the precipitation rates on a metallic surface calculated from the slope of CA curve without and with inhibitor, respectively.

\subsection{Morphology analysis}

The morphologies of $\mathrm{CaCO}_{3}$ crystals formed in the absence or presence of inhibitor were investigated by scanning electronic microscopy (SEM) using a FEG-SEM imaging with secondary electrons (FEG-SEM Zeiss ultra55 microscope operated at $10 \mathrm{kV}$ ).

The crystalline forms of $\mathrm{CaCO}_{3}$ and their molar fractions were determined by $\mathrm{X}$-ray diffraction (XRD) with a Panalytical Diffractometer using the $\mathrm{Cu}-\mathrm{K} \alpha$ radiation $(1.52 \AA)$ at room temperature. The different polymorphs of $\mathrm{CaCO}_{3}$ were determined and quantified as previously described [16]. Intensities of the diffraction peaks at $2 \theta=29.5^{\circ}\left(\mathrm{I}_{\mathrm{c}}{ }^{104}\right)$ and at $2 \theta=25^{\circ}\left(\mathrm{I}_{\mathrm{v}}{ }^{110}\right)$ were used to quantify the calcite and vaterite polymorphs respectively. The molar ratios of calcite $x_{c}$ and vaterite $x_{v}$ in the different samples were given by the following equations [32]:

$\frac{I_{c}^{104}}{I_{v}^{110}}=7.691 \times \frac{x_{c}}{x_{v}}$ 


\section{Results and discussion}

3.1. Influence of inhibitors on the precipitation time and the growth rate in solution (FCP methods)

The antiscaling properties of $H$. undatus solution and citric acid were investigated by using the FCP method. The resistivity and $\mathrm{pH}$ evolutions over time, in the absence and presence of inhibitor, are presented in Figure 1.

A

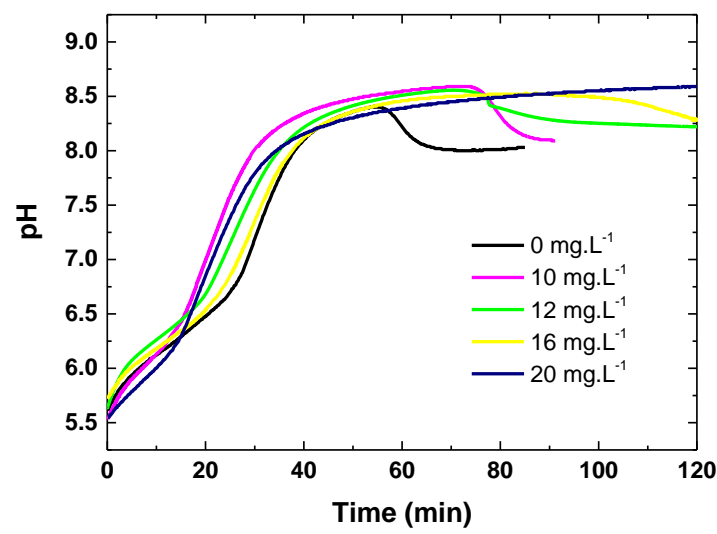

$\mathrm{C}$

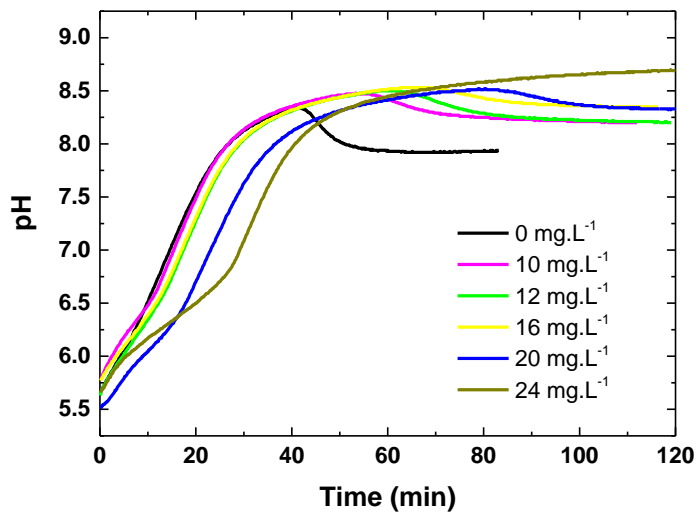

B

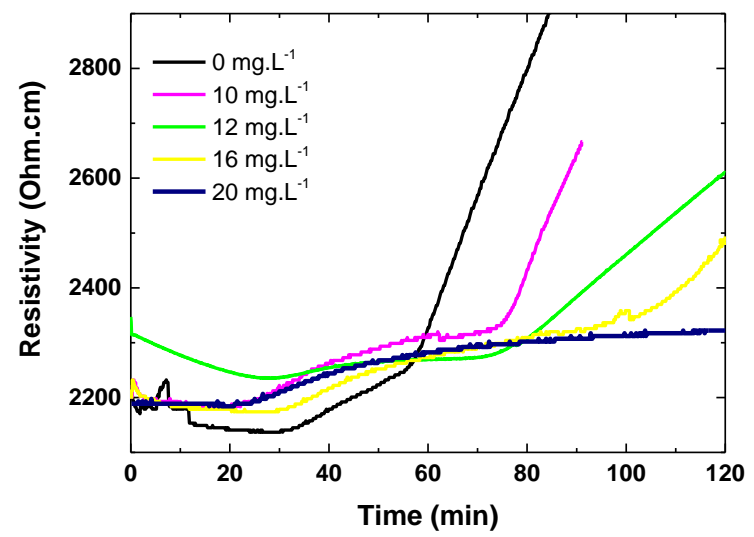

$\mathrm{D}$

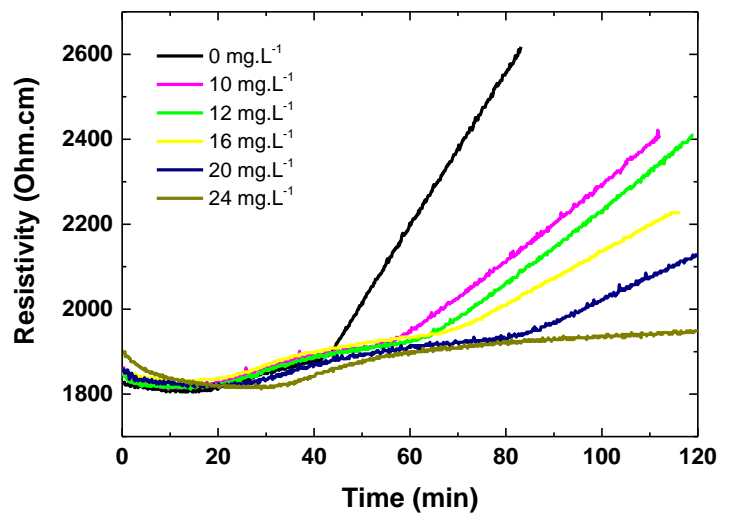

Figure 1: pH-time curves and resistivity-time curves for (A and B) Hylocereus undatus solution and (C and D) citric acid respectively, at different concentrations, in synthetic water containing initially $\left[\mathrm{Ca}^{2+}\right]=100 \mathrm{mg} \cdot \mathrm{L}^{-1}, 30{ }^{\circ} \mathrm{C}$, stirring rate $850 \mathrm{rpm}$. 
The FCP method is a convenient tool to evaluate the precipitation time and the growth rate of $\mathrm{CaCO}_{3}$ formation in solution, and to compare the influence of inhibitors concentration on the nucleation/growth processes [27]. Three distinct regions were observed in the curves $\mathrm{pH}$ versus time $[29,33]$. In the first part of the curve, the $\mathrm{pH}$ slightly increased, which corresponded to the formation of pair hydrated $\mathrm{Ca}^{2+}$ and $\mathrm{CO}_{3}{ }^{2-}$ ions. The second part, where a rapid increase of $\mathrm{pH}$ until a maximum value is observed, is characterized by the nucleation step. This step corresponds to the formation of $\mathrm{CaCO}_{3}$ nuclei in solution. Then, the $\mathrm{pH}$ decreases over time until reaching a constant value. This third step corresponds to the homogeneous precipitation where $\mathrm{CaCO}_{3}$ crystals grow in size and in number in solution $[29,33]$. The same trends were observed in the curves resistivity as a function of time.

The precipitation time $\left(t_{p}\right)$ was determined at the maximum of the curve of $\mathrm{pH}$ vs time. The growth rate of $\mathrm{CaCO}_{3}$ crystals in solution was assessed by the slope of the linear part of the resistivity curve. The first part of the curve resistivity vs time corresponds to the nucleation step. In this case, the resistivity remains constant. The second part of the curve corresponds to the homogeneous precipitation of $\mathrm{CaCO}_{3}$ in solution and is related to an increase of resistivity. All FCP results are summarized in Table 1.

Table 1: FCP results for $H$. undatus solution and citric acid. C: concentration; $t_{p}$ : precipitation time.

\begin{tabular}{ccc}
\hline $\mathrm{C}\left(\mathrm{mg} . \mathrm{L}^{-1}\right)$ & $t_{p}(\mathrm{~min})$ & $t_{p}(\mathrm{~min})$ \\
& H. undatus solution & Citric acid \\
\hline 0 & 50 & 43 \\
\hline 10 & 72 & 56 \\
\hline 12 & 74 & 63 \\
\hline 16 & 106 & 67 \\
\hline
\end{tabular}




\begin{tabular}{lll}
\hline 20 & - & 80 \\
\hline 24 & - & - \\
\hline
\end{tabular}

The evolution of inhibition efficiencies for $H$. undatus solution and citric acid as a function of inhibitor concentration is shown in Figure 2:

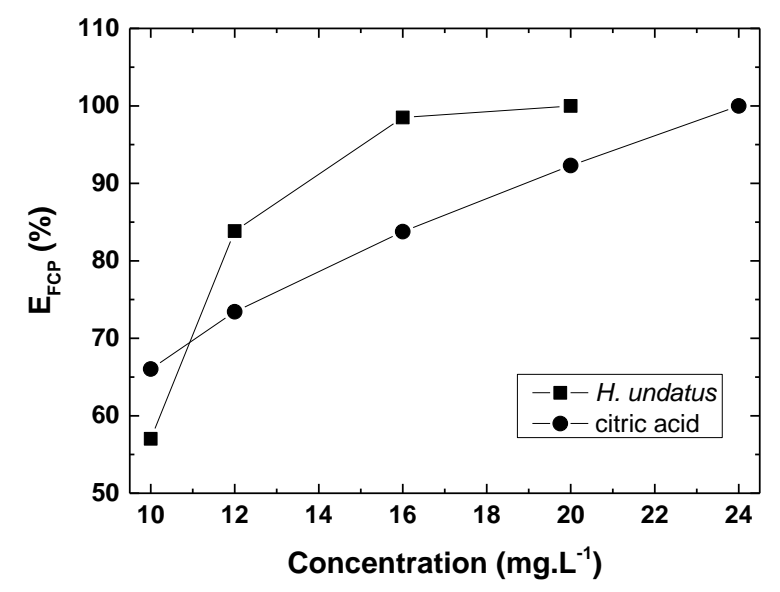

Figure 2: Evolution of the inhibition efficiency $\mathrm{E}_{\mathrm{FCP}}$ as a function of the inhibitor concentration for (-ם-) H. undatus solution and (-๑-) citric acid.

In the absence of inhibitor ( $H$. undatus solution or citric acid), the precipitation time was approximately $45 \mathrm{~min}$. In the presence of inhibitor, a delay of the precipitation time was observed (Figure 1-A and 1-C). For instance, the precipitation time was 98 min for H. undatus and $67 \mathrm{~min}$ for citric acid at a concentration of $16 \mathrm{mg} . \mathrm{L}^{-1}$. Therefore, both inhibitors acted as nucleation inhibitors, and $H$. undatus was more efficient to delay the homogeneous precipitation step.

In the homogeneous precipitation step, the growth rate of $\mathrm{CaCO}_{3}$ is related to the slope of the resistivity curve and clearly decreased in the presence of scale inhibitor, (Figure 1-B and 1-D). The homogeneous precipitation was considerably slowed down with the increase of inhibitor concentration. Therefore, the $H$. undatus solution and citric acid also acted as $\mathrm{CaCO}_{3}$ precipitation inhibitors. 
The inhibition was complete when no increase of resistivity (or no decrease of $\mathrm{pH}$ ) was observed. The optimal concentration to inhibit the formation of $\mathrm{CaCO}_{3}$ in solution was $20 \mathrm{mg} . \mathrm{L}^{-}$ ${ }^{1}$ and $24 \mathrm{mg} . \mathrm{L}^{-1}$ for $H$. undatus solution and citric acid, respectively. Therefore, H. undatus solution was more efficient than citric acid towards scaling inhibition. For instance, at a concentration of $12 \mathrm{mg} . \mathrm{L}^{-1}$, the inhibition efficiencies were $84 \%$ and $73 \%$ for $\mathrm{H}$. undatus solution and citric acid, respectively (Figure 2). As H. undatus solution was efficient at low concentration, it could be a good alternative to chemicals used in industrial applications.

The same phenomenon has been observed with Gambier extract [17], for which the inhibition effect on $\mathrm{CaCO}_{3}$ scale formation increased with the concentration of the Gambier extract. They interpreted this result by the fact that a chelating reaction occurred between $\mathrm{Ca}^{2+}$ and the main compounds in Gambier extract such as quercetin, catechin and tannic acid. They assumed that the microcrystalline of $\mathrm{CaCO}_{3}$ surrounded by ligands with similar charges repelled each other, preventing the formation of crystal nucleus, and reducing the $\mathrm{CaCO}_{3}$ crystal growth rate.

In the case of citric acid, Reddy and Hoch [34] have highlighted that the calcite growth rate at $25^{\circ} \mathrm{C}$ was slowed down in the presence of citric acid at $10 \mathrm{mg} \cdot \mathrm{L}^{-1}$. This was probably due to the presence of carboxylic groups, which could adsorb on the growth sites of $\mathrm{CaCO}_{3}$ crystals, preventing the formation of $\mathrm{CaCO}_{3}$ in solution.

\subsection{Influence of the scale inhibitors on the morphology of the precipitates}

After each FCP experiment, $\mathrm{CaCO}_{3}$ crystals formed in the bulk were retrieved by filtering the solution. The morphologies of these crystals, obtained in the absence or presence of inhibitors, were observed by SEM and the crystalline phases were investigated by XRD (Figure 3). 

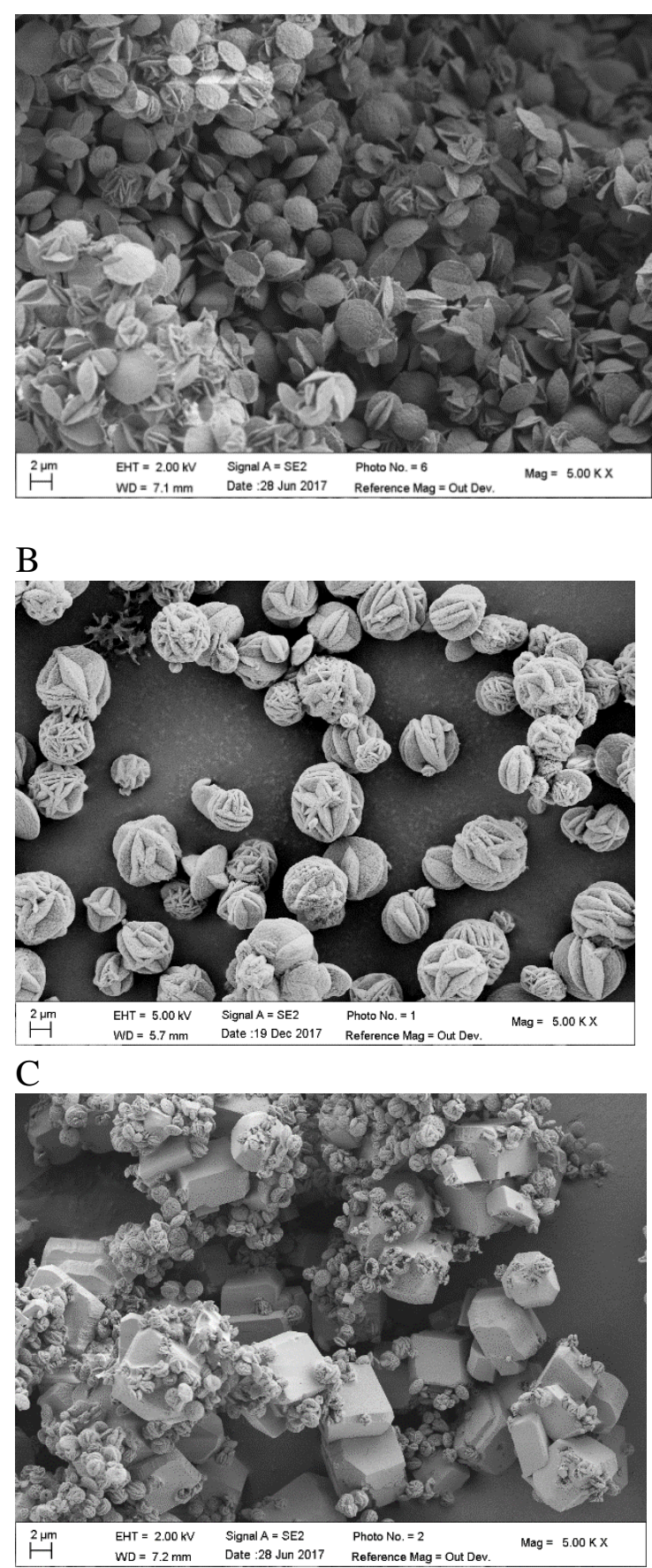

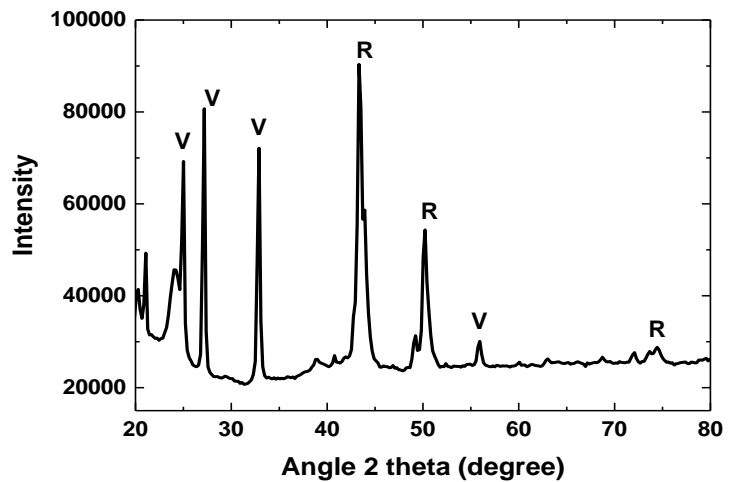

$\mathrm{E}$

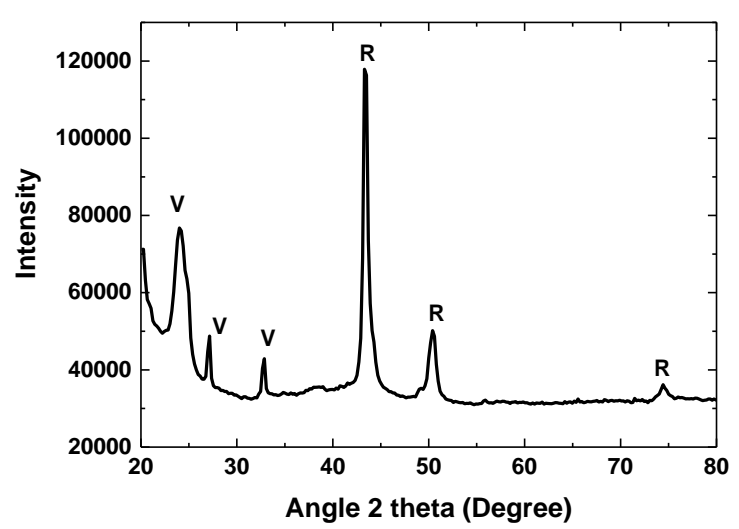

$\mathrm{F}$

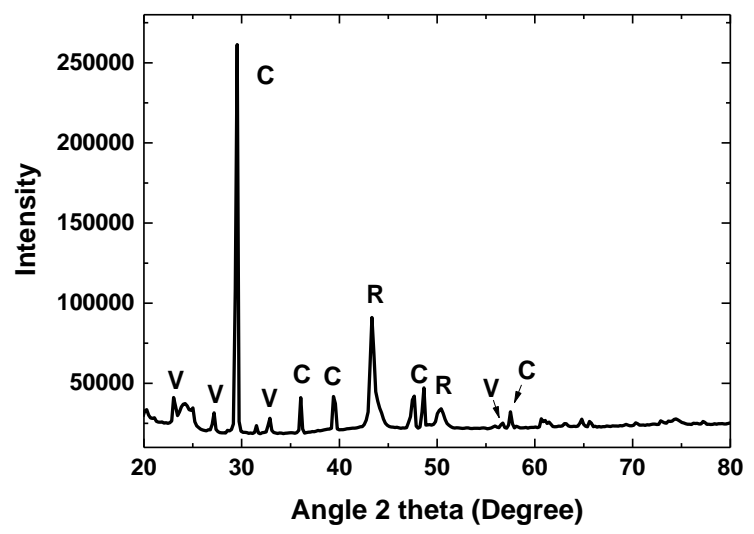

Figure 3: (A to C) SEM images and (D to F) XRD spectra for $\mathrm{CaCO}_{3}$ crystals obtained from FCP experiments: with (A and D) no inhibitor, (B and E) H. undatus solution at $12 \mathrm{mg} . \mathrm{L}^{-1}$, and (C and F) citric acid at $12 \mathrm{mg} . \mathrm{L}^{-1}, \mathrm{R}$ : Reference, V: Vaterite, C: Calcite.

As shown in Figure 3-A, in the absence of inhibitor, only vaterite polymorph, a metastable form of $\mathrm{CaCO}_{3}$, was observed, which was confirmed by the XRD spectrum (Figure 3-D). 
In the presence of $H$. undatus solution at $12 \mathrm{mg} . \mathrm{L}^{-1}$ (Figure 3-B), only vaterite polymorph was found, which was confirmed by the results obtained by XRD analysis (Figure 3-E). The $\mathrm{CaCO}_{3}$ crystals were distorted and less numerous, compared to the crystals obtained without inhibitor. In the presence of citric acid at $12 \mathrm{mg} . \mathrm{L}^{-1}$, a mixture of vaterite and calcite polymorphs was obtained, and the size of vaterite particles was much smaller than those obtained in the absence of inhibitor. This result was confirmed by the analysis of the XRD spectrum (Figure 3-F) that revealed characteristic peaks of calcite and vaterite. The molar ratios of vaterite and calcite, calculated from Eqs. (3) and (4) were 50.5\% and 49.5\%, respectively. In addition, calcite crystals were distorted in the presence of citric acid (Figure 3-C). This could be explained by the presence of carboxylic groups in the structure of citric acid, which could easily adsorb on the surface of the $\mathrm{CaCO}_{3}$ crystal, reducing their growth and modifying their geometry [35]. More generally, surface complexation can occur between the carboxylate groups of small organic molecules and hydrated calcium atoms located on the $\mathrm{CaCO}_{3}$ surface exposed to the liquid phase [36]. Kitano and Hood [37] demonstrated that small quantities of sodium citrate favored the formation of calcite. It seemed that $H$. undatus solution did not contain compounds that generate calcite polymorph.

\subsection{Influence of the scale inhibitors on $\mathrm{CaCO}_{3}$ formation on a metallic surface (CA methods)}

The influence of $H$. undatus solution and citric acid on the $\mathrm{CaCO}_{3}$ formation on a metallic surface was investigated by CA experiments. The Figures 4-A and 4-B show the current evolution over time in the absence and presence of $H$. undatus solution and citric acid, respectively. 

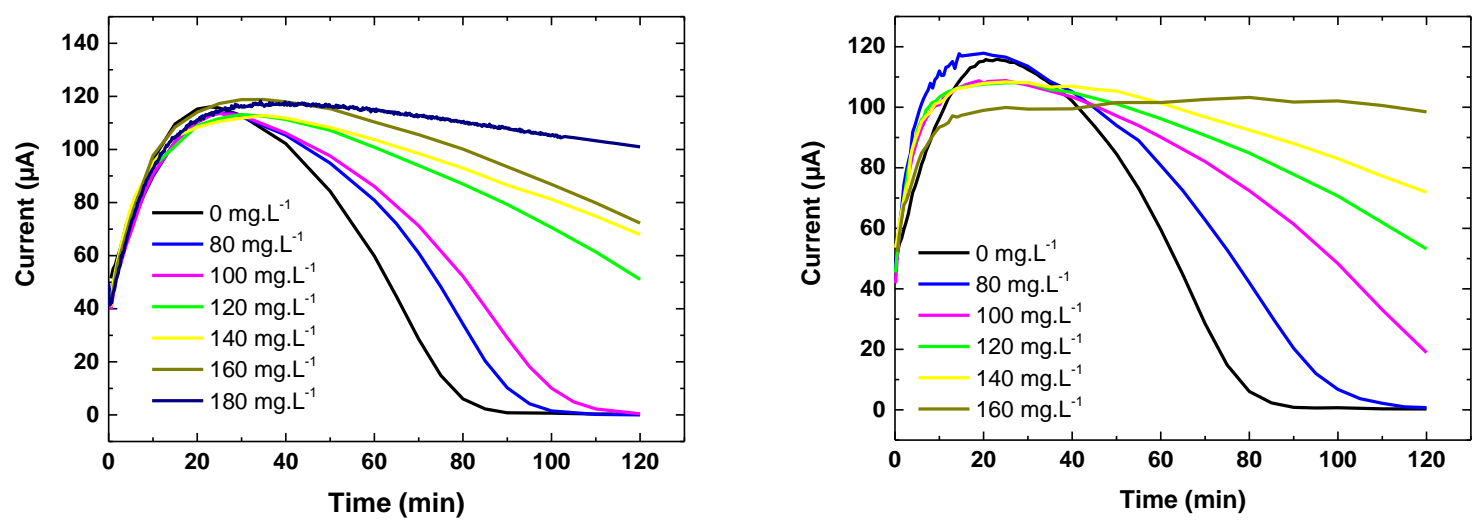

Figure 4: Evolution of current versus time, in the presence of (A) H. undatus solution and (B) citric acid at different concentrations. Applied potential: -1 V/SCE, copper rotating disc electrode working at $500 \mathrm{rpm}, 30^{\circ} \mathrm{C}$, synthetic water $\left[\mathrm{Ca}^{2+}\right]=100 \mathrm{mg} \cdot \mathrm{L}^{-1}$; initial $\mathrm{pH}=5.6$.

In the absence of inhibitor, an isolating $\mathrm{CaCO}_{3}$ layer was progressively formed on the electrode surface. Therefore, the current decreased until reaching a stable residual value $(\sim 15 \mu \mathrm{A})$, which means that the electrode was totally covered. The scaling time was the time necessary to cover the electrode and the precipitation rate was determined by the slope of the current curve versus time. The scaling time is defined as the intersection of the tangent at the inflexion point of the CA curve and the time axis [38]. In the absence of inhibitor, the scaling time was $80 \mathrm{~min}$. The scaling time increased when the inhibitors concentration increased. For instance, for a $H$. undatus solution and citric acid at $80 \mathrm{mg} . \mathrm{L}^{-1}$, it was 100 and $110 \mathrm{~min}$ respectively. Moreover, the surface coverage by a layer of $\mathrm{CaCO}_{3}$ decreased when the concentration of inhibitor increased.

When no decrease of current was observed over time, no precipitation of $\mathrm{CaCO}_{3}$ on the metallic surface occurred and the scaling inhibition was total. The optimal concentrations to inhibit totally the $\mathrm{CaCO}_{3}$ formation on a metallic surface were 180 and $160 \mathrm{mg} . \mathrm{L}^{-1}$, for H. undatus solution and citric acid respectively (Figure 4). 
In order to quantify the scale inhibition properties of $H$. undatus solution and citric acid, the efficiency of inhibitor $\mathrm{E}_{\mathrm{CA}}$ was calculated according to Eq. (2), and the precipitation rate on the metallic surface was assessed from the slope of CA curves.

The evolution of the inhibition efficiency $\mathrm{E}_{\mathrm{CA}}$ as a function of the inhibitor concentration is shown in Figure 5:

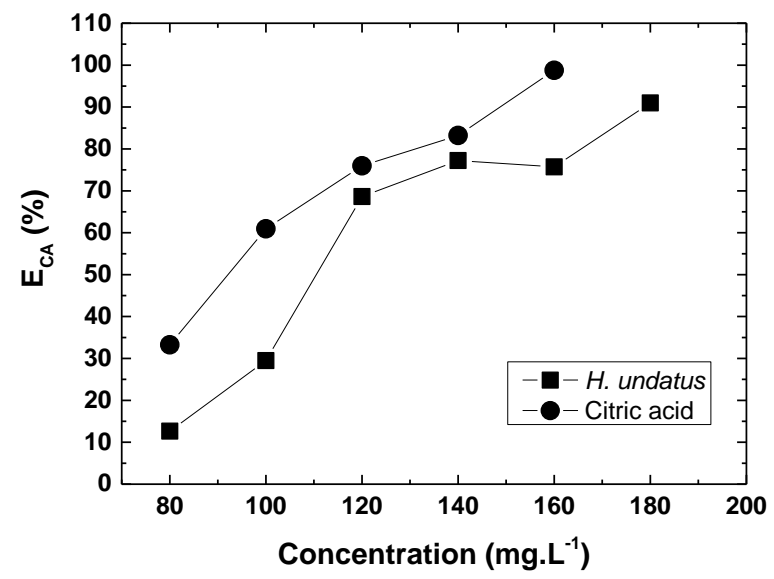

Figure 5: Evolution of the inhibition efficiency $\mathrm{E}_{\mathrm{CA}}$ as a function of the inhibitor concentration for (-曰-) H. undatus solution and (-๑-) citric acid.

For a given concentration, the inhibition efficiency of citric acid was higher than that of $H$. undatus solution (Figure 5). The inhibition efficiency of $H$. undatus solution and citric acid was $100 \%$ for a concentration of 180 and $160 \mathrm{mg} . \mathrm{L}^{-1}$, respectively. Accordingly, it seemed that citric acid was more efficient than $H$. undatus solution to inhibit the $\mathrm{CaCO}_{3}$ formation on a metallic surface. It should be noticed that $H$. undatus solution was more efficient than citric acid to inhibit the $\mathrm{CaCO}_{3}$ formation in solution. The effect of $\mathrm{pH}$ on the adsorption of citric acid on $\mathrm{CaCO}_{3}$ particles has been investigated by Bassioni [39]. The results have shown that citric acid anions could adsorb on $\mathrm{CaCO}_{3}$ crystals at $\mathrm{pH} 9$ and 12.5 and acted as inhibitors at high $\mathrm{pH}$.

\section{Conclusion}


In this work, the antiscaling properties of an aqueous solution of $H$. undatus towards $\mathrm{CaCO}_{3}$ formation was estimated by using FCP and CA methods. It allows a fair evaluation of the antiscaling properties in two complementary conditions to be done in a short time.

In FCP experiment (at $30{ }^{\circ} \mathrm{C}$ in carbonically pure water with $\left[\mathrm{Ca}^{2+}\right]=100 \mathrm{mg} / \mathrm{L}$ ), the precipitation of $\mathrm{CaCO}_{3}$ in solution was totally inhibited for 20 and $24 \mathrm{mg} . \mathrm{L}^{-1}$ of $H$. undatus and citric acid, respectively. The SEM images and XRD analysis showed that vaterite polymorph was preferentially formed in the presence of $H$. undatus solution whereas vaterite and calcite appeared with citric acid.

According to the CA results, both $H$. undatus solution and citric acid are able to inhibit the formation of $\mathrm{a} \mathrm{CaCO}_{3}$ layer on a metallic surface with an optimal concentration of 180 and 160 mg. $L^{-1}$, respectively.

H. undatus solution is a green inhibitor which could act at low concentration, thus it could be interesting for some industrial applications. It can be easily obtained from the aerial part from Dragon fruit tree, which constitutes a potential source of renewable raw material. Moreover, no difficult process was required to obtain $H$. undatus solution as the aqueous extract was obtained by infusion in hot water. Further work is needed to identify the compounds in H. undatus solution responsible for the inhibition of $\mathrm{CaCO}_{3}$ precipitation.

\section{Acknowledgments}

This work was supported by Veolia Eau d'Ile de France, Research and Development, France and EPF-Graduate School of Engineering, France. Jonathan Sadoun (Université Paris Descartes) is gratefully acknowledged for fruitful discussions. The authors thank Françoise Pillier, Cyrille Bazin and Axel Desnoyers de Marbaix (LISE) for technical assistance. 


\section{Figure captions}

Figure 1: pH-time curves and resistivity-time curves for (A and B) Hylocereus undatus solution and (C and D) citric acid respectively, at different concentrations, in synthetic water containing initially $\left[\mathrm{Ca}^{2+}\right]=100 \mathrm{mg} \cdot \mathrm{L}^{-1}, 30{ }^{\circ} \mathrm{C}$, stirring rate $850 \mathrm{rpm}$.

Figure 2: Evolution of the inhibition efficiency $\mathrm{E}_{\mathrm{FCP}}$ as a function of the inhibitor concentration for (-曰-) H. undatus solution and (-๑-) citric acid.

Figure 3: (A to C) SEM images and (D to F) XRD spectra for $\mathrm{CaCO}_{3}$ crystals obtained from FCP experiments: with (A and D) no inhibitor, (B and E) H. undatus solution at $12 \mathrm{mg} . \mathrm{L}^{-1}$, and (C and F) citric acid at $12 \mathrm{mg} . \mathrm{L}^{-1}$, R: Reference, V: Vaterite, C: Calcite.

Figure 4: Evolution of current versus time, in the presence of (A) H. undatus solution and (B) citric acid at different concentrations. Applied potential: -1 V/SCE, copper rotating disc electrode working at $500 \mathrm{rpm}, 30^{\circ} \mathrm{C}$, synthetic water $\left[\mathrm{Ca}^{2+}\right]=100 \mathrm{mg} . \mathrm{L}^{-1}$; initial $\mathrm{pH}=5.6$.

Figure 5: Evolution of the inhibition efficiency $\mathrm{E}_{\mathrm{CA}}$ as a function of the inhibitor concentration for (-ם-) H. undatus solution and (-๑-) citric acid.

\section{Table captions}

Table 1: FCP results for $H$. undatus solution and citric acid. C: concentration; $t_{p}$ : precipitation time. 


\section{References}

[1] K. D. Demadis, E. Mavredaki, A. Stathoulopoulou, E. Neofotistou, C. Mantzaridis, Industrial water systems: problems, challenges and solutions for the process industries, Desalination 213 (2007) 38-46.

[2] Z. Mohammadi, M. Rahsepar, The use of green Bistorta officinalis extract for effective inhibition of corrosion and scale formation problems in cooling water system, Journal of Alloys and Compounds 770 (2019) 669-678.

[3] A. L. Kavitha, T. Vasudevan, H. Gurumallesh Prabu, Evaluation of synthesized antiscalants for cooling water system application, Desalination 268 (2011) 38-45.

[4] S. N. Kazi, G. G. Duffy, X. D. Chen, Mineral scale formation and mitigation on metals and a polymeric heat exchanger surface, Applied Thermal Engineering 30 (2010) 2236-2242.

[5] F.-A. Setta, A. Neville, Efficiency assessment of inhibitors on $\mathrm{CaCO}_{3}$ precipitation kinetics in the bulk and deposition on a stainless steel surface(316 L), Desalination 281 (2011) 340 347.

[6] M. Donnet, A. Aimable, J. Lemaître, P. Bowen, Contribution of aggregation to the growth mechanism of seeded calcium carbonate precipitation in the presence of polyacrylic acid, $\mathrm{J}$. Phys. Chem. B 114 (2010) 12058-12067.

[7] Z. Liu, Y. Sun, X. Zhou, T. Wu, Y. Tian, Y. Wang, Synthesis and scale inhibitor performance of polyaspartic acid, Journal of Environmental Sciences 2011, 23 (Supplement) S153-S155.

[8] S. Ouhenia, D. Chateigner, M.A. Belkhir, E. Guilmeau, C. Krauss, Synthesis and scale inhibitor performance of polyaspartic acid, Journal of Crystal Growth 310 (2008) 2832-2841. 
[9] Y. Ji, Y. Chen, J. Le, M. Qian, Y. Huan, W. Yang, X. Yin, Y. Liu, X. Wang, Y. Y. Chen, Highly effective scale inhibition performance of amino trimethylenephosphonic acid on calcium carbonate, Desalination 422 (2017) 165-173.

[10] J. A. Camargo, A. Alonso, Ecological and toxicological effects of inorganic nitrogen pollution in ecosystems: a global assessment, Environment International 32 (2006) 831-849.

[11] A.E. Elkholy, F. El-Taib Heakal, A.M. Rashad, K. Zakaria, Monte Carlo simulation for guar and xanthan gums as green scale inhibitors, Journal of Petroleum Science and Engineering 166 (2018) 263-273.

[12] M. Chaussemier, E. Pourmohtasham, D. Gelus, N. Pécoul, H. Perrot, J. Lédion , H. CheapCharpentier, O. Horner, State of art of natural inhibitors of calcium carbonate scaling. A review article, Desalination 356 (2015) 47-55.

[13] D. Hasson, H. Shemer, A. Sher, State of the art of friendly "green" scale control inhibitors: a review article, Ind. Eng. Chem. Res. 50 (2011) 7601-7607.

[14] P.T. Anastas, J.C. Warner, Green Chemistry: Theory and Practice, vol.11, Oxford University Press, NewYork (1998).

[15] O. Horner, H. Cheap-Charpentier, X. Cachet, H. Perrot, J. Lédion, D. Gelus, N. Pécoul, M. Litaudon, F. Roussi, Antiscalant properties of Herniaria glabra aqueous solution, Desalination 409 (2017) 157-162.

[16] H. Cheap-Charpentier, D. Gelus, N. Pécoul, H. Perrot, J. Lédion, O. Horner, J. Sadoun, X. Cachet, M. Litaudon, F. Roussy, Antiscalant properties of Spergularia rubra and Parietaria officinalis aqueous solutions, Journal of Crystal Growth 443 (2016) 43-49.

[17] Suharso, T. Reno, T. Endaryanto, Buhani, Modification of Gambier extracts as green inhibitor of calcium carbonate $\left(\mathrm{CaCO}_{3}\right)$ scale formation, Journal of Water Process Engineering 18 (2017) $1-6$. 
[18] J. Lédion, B. François, J. Vienne, Characterization of the scaling properties of water by fast controlled precipitation test, Eur. J. Water Qual. 28 (1997) 15-35.

[19] G. Gauthier, Y. Chao, O. Horner, O. Alos-Ramos, F. Hui, J. Lédion, H. Perrot, Application of the Fast Controlled Precipitation method to assess the scale-forming ability of raw river waters, Desalination 299 (2012) 89-95.

[20] C. Gabrielli, M. Keddam, H. Perrot, A. Khalil, R. Rosset, M. Zidoune, Characterization of the efficiency of antiscale treatments of water Part I: Chemical processes, J. Appl. Electrochem. $26(1996) 1125-1132$.

[21] L. Xu, Y. Zhang, L. Wang, Structure characteristics of a water-soluble polysaccharide purified from dragon fruit (Hylocereus undatus) pulp, Carbohydrate Polymers 146 (2016) 224230.

[22] Y. Yi, Q. W. Zhang, S. L. Li, Y. Wang, W. C. Ye, J. Zhao, Y. T. Wanga, Simultaneous quantification of major flavonoids in Bawanghua, the edible flower of Hylocereus undatus using pressurised liquid extraction and high performance liquid chromatography, Food Chem.135 (2012), 528-533.

[23] D. H. Suh, S. Lee, D. Y. Heo, Y. S. Kim, S. K. Cho, S. Lee, and C. H. Lee, J. Agric., Metabolite Profiling of Red and White Pitayas (Hylocereus polyrhizus and Hylocereus undatus) for Comparing Betalain Biosynthesis and Antioxidant Activity, Food Chem. 62 (2014), 8764-8771.

[24] N. Wada, K. Kanamura, T. Umegaki, Effects of carboxylic acids on calcite formation in the presence of $\mathrm{Mg}^{2+}$ ions, Journal of Colloid and Interface Science 212, (1999) 357-364.

[25] S. Ghizellaoui, S. Ghizellaoui, H. Semineras, Inhibition of scale formation by electrochemical means in the presence of a green inhibitor; citric acid, Journals of Materials and Environmental Sciences 8 (2017) 2105-2111. 
[26] C.G. Sinn, R. Dimova, M. Antonietti, Isothermal titration calorimetry of the polyelectrolyte/water interaction and binding of $\mathrm{Ca}^{2+}$ : effects determining the quality of polymeric scale inhibitors, Macromolecules 37 (2004) 3444-3450.

[27] D. Peronno, H. Cheap-Charpentier, O. Horner, H. Perrot, Study of the inhibition effect of two polymers on calcium carbonate formation by fast controlled precipitation method and quartz crystal microbalance, J. Water Process Eng. 7 (2015) 11-20.

[28] H. Cheap-Charpentier, O. Horner, J. Lédion, H. Perrot, Study of the influence of the supersaturation coefficient on scaling rate using the pre-calcified surface of a quartz crystal microbalance, Water Research 142 (2018) 347-353.

[29] Y. Chao, O. Horner, P. Vallée, F. Meneau, O. Alos-Ramos, F. Hui, M. Turmine, H. Perrot, J. Lédion, In situ probing calcium carbonate formation by combining Fast Controlled Precipitation method and small-angle X-ray scattering, Langmuir 30 (2014) 3303-3309.

[30] M.M. Tlili, M. Benamor, C. Gabrielli, H. Perrot, B. Tribollet, Influence of the interfacial pH on electrochemical $\mathrm{CaCO}_{3}$ precipitation, J. Electrochem. Soc.150 (2003) C765-C771.

[31] C. Deslouis, Interfacial $\mathrm{pH}$ measurement during reduction of dissolved oxygen in a submerged impinging jet cell, J. Appl. Electrochem. 27 (1997) 482-492.

[32] C.G. Kontoyannis, and N.V. Vagenas, Calcium carbonate phase analysis using XRD and FT-Raman spectroscopy, Analyst 125 (2000) 251-255.

[33] J. Lédion, C. Braham, F. Hui, Anti-scaling properties of copper, Journal of Water Supply: Research and Technology - AQUA 51.7 (2002) 389-398.

[34] M.M. Reddy, A.R. Hoch, Calcite crystal growth rate inhibition by polycarboxylic acids, Journal of Colloid and Interface Science 235 (2001) 365-370.

[35] N. Wada, K. Kanamura, T. Umegaki, Effects of carboxylic acids on the crystallization of calcium carbonate, Journal of Colloid and Interface Science 233 (2001) 65-72.

[36] J. Planck, G. Bassioni, Adsorption of carboxylate on $\mathrm{CaCO}_{3}$ surface, Zeitschrift für 
Naturforschung B 62b (2007) 1277-1284.

[37] Y. Kitano and D. W. Hood, The influence of organic material on the polymorphic crystallization of calcium carbonate, Geochimica et Cosmochimica Acta 29 (1965) 29-41.

[38] F. Hui, J. Lédion, Evaluation methods for the scaling power of water, Journal European of water quality 33 (2002) 1-27.

[39] G. Bassioni, Mechanistic aspects on the influence of inorganic anion adsorption on oilfield scale inhibition by citrate, Journal of Petroleum Science and Engineering 70 (2010) 298-301. 